\title{
Pacific Islands Families Study: Risk and Protective Factors Associated with Delinquent Behaviour in Pacific 11-Year-Olds
}

\author{
Janis Paterson ${ }^{*}$, El-Shadan Tautolo², Leon Iusitini², Steve Taylor ${ }^{3}$, Richard Siegert ${ }^{4}$ \\ ${ }^{1}$ Faculty of Health \& Environmental Sciences, Auckland University of Technology, Auckland, New Zealand \\ ${ }^{2}$ Pacific Islands Families Study, Auckland, New Zealand \\ ${ }^{3}$ Department of Biostatistics and Epidemiology, Auckland University of Technology, Auckland, New Zealand \\ ${ }^{4}$ Department of Psychology, Auckland University of Technology, Auckland, New Zealand

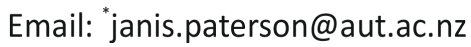

Received 4 April 2016; accepted 27 June 2016; published 30 June 2016

Copyright (C) 2016 by authors and Scientific Research Publishing Inc.

This work is licensed under the Creative Commons Attribution International License (CC BY).

http://creativecommons.org/licenses/by/4.0/

(c) (i) Open Access

\section{Abstract}

This paper examines risk and protective factors associated with delinquent behaviour among Pacific youth living in New Zealand (NZ). As part of the longitudinal Pacific Islands Families study, 11-year-olds Pacific youth participated in multidisciplinary interviews which included questions about involvement in delinquent behaviours. Peer pressure was the strongest risk factor for delinquency, and protective factors were higher self-perception, teacher evaluation scores, and perceived support from friends. Pacific boys reported significantly more delinquent behaviours than Pacific girls. Maternal acculturation was significantly associated with the delinquent behaviour of youth. Youth of mothers categorized as integrators (high Pacific/high NZ) having lower odds for delinquency than youth of mothers categorized as assimilators (low Pacific/high NZ). Youth from the largest Pacific Island groups (Samoa, Tonga and Cook Islands) were also significantly more likely to engage in delinquent behaviour than those from smaller island groups. Implications of these findings for prevention and further research are discussed.

\section{Keywords}

Pacific Youth, Delinquency, Longitudinal Studies, Risk Factors

\footnotetext{
${ }^{*}$ Corresponding author.
}

How to cite this paper: Paterson, J., Tautolo, E.-S., Iusitini, L., Taylor, S., \& Siegert, R. (2016). Pacific Islands Families Study: Risk and Protective Factors Associated with Delinquent Behaviour in Pacific 11-Year-Olds. Psychology, 7, 953-964. 


\section{Introduction}

Pacific people living in New Zealand (NZ) are ethnically heterogeneous (Samoan, 49\%; Cook Islands Māori, 21\%; Tongan, 20\%; and Niuean, 8\%), rapidly growing, youthful, and highly urbanised (Statistics New Zealand, 2013). Waves of migration to NZ took place in the 1950's and 1980's when Pacific people arrived from Samoa, Tonga, Cook Islands, Niue, Fiji, and the Tokelau's. Pacific people actively participate in the NZ economy and have significant social, sporting, and cultural links across NZ society (Sang \& Ward, 2006). However, compared with the general population, Pacific people have higher rates of unemployment (Statistics New Zealand, 2013), lower household incomes (Perry, 2014), and higher rates of poverty (Boston \& Chapple, 2014).

Adolescence is a time when mental health issues such as anxiety and depression increase to distressing levels (Jose \& Schurer, 2010), and risk taking behaviours further jeopardise adolescent wellbeing in the short and long term (Begg \& Gulliver, 2008). Disruptive patterns of behaviour in childhood often set the stage for impulsive and antisocial behaviour (Office of the Prime Minister's Science Advisory Committee, 2011) and delinquency in adolescence, particularly in males (Broidy et al., 2003). Pacific youth in NZ are over-represented in negative social and health statistics (Ministry of Health, 2008). Research with Pacific youth has revealed intergenerational patterns in gang membership (Ioane, Lambie, \& Percival, 2013), exposure to binge drinking and violence in the home (Nakhid, 2009; Statistics New Zealand \& Ministry of Pacific Island Affairs, 2011), and compared to other youth in NZ, Pacific youth have lower educational achievement (Harkness, Murray, Parkin, \& Dalgety, 2005; Ministry of Business, Innovation, \& Employment, 2013), and are less likely to gain tertiary qualifications (Statistics New Zealand \& Ministry of Pacific Island Affairs, 2011).

Strong cultural links and healthy relationships with peers, family, and the wider community may be protective in reducing adolescent risk factors (Jose, Ryan, \& Pryor, 2012). This paper examines risk and protective factors associated with delinquent behaviour among Pacific youth living in NZ.

\section{Method}

\subsection{Participants}

The Pacific Islands Families (PIF) Study is following a cohort of Pacific children born in Auckland, NZ in 2000 and their parents. All potential participants were selected from births at one hospital where at least one parent identified as being of a Pacific ethnicity and was a NZ permanent resident. The original cohort included 1376 mothers of 1398 Pacific infants (including 44 twins). Children and their families have been visited when the children were aged 6 weeks, and 1, 2, 4, 6, 9, and 11 years. Compared with data available from Statistics New Zealand's 1996 and 2001 censuses, the inception cohort was broadly representative of the Pacific census figures (Paterson et al., 2008).

\subsection{Procedures}

At 11 years postpartum, primary caregivers (typically the mother) of the birth cohort were invited to participate in the seventh measurement wave of the PIF study. Once informed consent was obtained, they participated in interviews concerning family functioning and the health and development of their child. The adolescent participants were interviewed in the school setting (or at home in exceptional circumstances). A more detailed description of recruitment and procedures is available elsewhere (Paterson et al., 2008).

\subsection{Measures}

Delinquency: Twenty-four binary-response questions from three distinct psychometric measures were combined to measure delinquency as follows.

Youth Risk Behaviors: Fourteen questions based on LONGSCAN-developed questions (Thompson et al., 2011) relating to youth risk behaviours such as using alcohol or other substances, violent or delinquent behaviour.

Gang Involvement: Two items from a modified version of the Gang Membership Inventory (Pillen \& Hoewing-Roberson, 1992).

Bullying: Eight questions on perpetration of bullying; the definition and questions were drawn from the Revised Olweus Bully/Victim Questionnaire (OBVQ) (Olweus, 1996). Previous research has found good validity 
for self-reported delinquency and violent behavior from various measures (Williams \& Nowatzki, 2005).

Parenting: The Alabama Parenting Questionnaire (APQ) (Frick, Christian, \& Wooten, 1999) is a 42 item scale with five dimensions. They are: 1) Positive involvement; 2) Poor supervision and monitoring; 3) Use of positive discipline techniques; 4) Consistency of discipline; and 5) Use of corporal punishment. The average reliability across APQ scales is 0.68 and the psychometric properties are good. This includes criterion validity in differentiating clinical and non-clinical groups (Dadds, Maujean, \& Fraser, 2003).

Maternal acculturation: The General Ethnicity Questionnaire (GEQ) (Tsai, Ying, \& Lee, 2000) is based on four different varieties of acculturation: assimilation (replacing Pacific with NZ culture), integration (identification with both cultures), separation (maintaining only Pacific culture), and marginalization (withdrawal from both cultures). For the specific purposes of the PIF Study, the scale was shortened and slightly modified thereby developing the Pacific (PI Acculturation) and NZ (NZ Acculturation) versions of the GEQ (Borrows, Williams, Schluter, Paterson, \& Langitoto Helu, 2011). The internal consistency of the measure was examined using Cronbach's $\alpha$, and was found to be acceptable ( $\alpha=0.81$ and 0.83 for the NZ Acculturation and PI Acculturation respectively).

Perception of self: Children's self-perceptions of their physical abilities, parental relationships, peer relationships, general self-perceptions and school performance were assessed using the Self-Description Questionnaire (Marsh, 1994). Responses to the 10 questions were made on a five-point Likert scale and an overall self-perception score was derived as the average of responses. Strong construct validity has been demonstrated (Marsh, 1994).

Cognitive development: The Wechsler Intelligence Scale for Children-Fourth edition (WISC-IV) measures intellectual functioning. Scores from four subtests ("vocabulary", "similarities", "block design" and "matrix reasoning”) were combined to provide a Wechsler Abbreviated Scale of Intelligence (WASI) score. The WISC has robust psychometric properties (Wechsler, 2003).

School performance: Teachers completed a short assessment on a five-point scale $(1=$ "very poor" to $5=$ "excellent") of the child's performance on reading, oral language, written language and mathematics. The four scores were averaged to form a single score (Cronbach's $\alpha=0.92$ ).

Language spoken at home: Children were asked whether English or a Pacific language was normally spoken in their home.

Church involvement: Children were asked whether they attend church regularly.

Peer pressure: Children were asked whether they "hang-out with a group of friends on a regular basis" and, if so, had they "ever been pressured by other members of this group into doing something that was not good, even though you didn't want to”.

Perceived social support: The Multidimensional Scale of Perceived Social Support (MSPSS) is comprised of 12 items and measures perceptions of support from three sources: Family, Friends, and a Significant Other (Zimet, Dahlem, Zimet, \& Farley, 1988). Across many studies the MSPSS has been shown to have good internal and test re-test reliability, good validity and a fairly stable factorial structure (Canty-Mitchell \& Zimet, 2000).

Externalising child behaviour: The 120-item Child Behaviour Checklist (CBCL/6-18) was used in the six and nine-year-olds maternal interviews (Achenbach \& Rescorla, 2000). The score for externalising behaviour is derived from 35 questions within two syndromes: aggression and rule breaking. The CBCL problem behavior scales were normed according to age and gender categories on both clinically referred and non-referred samples of children. To determine clinically relevant cases we used the Achenbach and Rescorla (2000) cut-off values. Extensive psychometric information based on multicultural comparisons is available (Rescorla et al., 2011). Cronbach's $\alpha$ values ranged from 0.76 to 0.93 within this cohort. Children with any evidence of previous clinical-range externalising behavior (at ages 6 or 9 years) were compared against those without such behavior.

Intimate partner violence: The Form R of the Conflict Tactics Scale (CTS) (Straus, 1979) was used to measure maternal intimate partner violence (IPV). Any positive response to questions in the six-item Severe Physical Violence subscale was used to indicate that the child had potentially been exposed to IPV in the home. Psychometric properties of the CTS scales are robust (Straus, 1990).

Maternal psychological distress: The 12-item General Health Questionnaire (GHQ12) (Goldberg \& Williams, 1988) is widely used to identify current psychological distress in adults at a particular point in time and has been used with maternal participants at every PIF data point. It screens for non-psychotic disorders and focuses on two major areas, the inability to carry out normal functions and the appearance of new and distressing psychological phenomena. Each item was recorded on a four-point Likert scale, such as from "not at all" up to "much 
more[less] than usual", which were assigned values 0 to 3 . Mothers with three or more responses having values 2 or 3 (a common "binary" method of scoring) were referred to in this study as symptomatic (of psychological distress). High validity coefficients for the GHQ12 of between 0.83 and 0.93 have been reported in a number of settings (Makowska, Merecz, Moscicka, \& Kolasa, 2002). Using Cronbach's $\alpha$ values the internal consistency of the maternal GHQ scores in the PIF Study were $0.87,0.85,0.83$, at ages 2, 4, and 6 years respectively.

Socio-demographics: The sex of the cohort child was recorded at the beginning of the longitudinal study, i.e. at birth. Likewise, baseline household income was used as a proxy for socio-economic status. Maternal age, marital status, highest education level, and smoking status were recorded concurrently with youth data collection. At age 11, children were asked to self-identify their ethnic identity, and those with multiple ethnic identities/affiliations were asked whether they thought this ever "made things difficult sometimes".

Maternal alcohol consumption: Alcohol consumption was assessed by the Alcohol Use Disorders Identification Test (Saunders, Aasland, \& Babor, 1993). Consumption was categorized into binary "drinking” and "nondrinking” categories.

\subsection{Data Analysis}

\subsubsection{Measuring Delinquency}

The 24 binary-response variables on delinquency were entered into a Rasch analysis (Rasch, 1960; Tennant \& Conaghan, 2007) to derive a logit score for each adolescent on a latent dimension measuring delinquency. Rasch models were fitted using the eRm package in R (Mair, Hatzinger, \& Maier, 2015). The use of the Rasch model ensures that the total score for delinquency represents a reliable, unidimensional, interval level score.

\subsubsection{Statistical Analysis}

Missing values in explanatory variables were dealt with using the technique of multiple imputation via chained equations (van Buuren \& Groothuis-Oudshoorn, 2011). Less than $0.6 \%$ of values were missing for all variables except for teacher evaluation scores (27\% missing). Thirty imputed data sets were generated. Due to a considerable skewness and floor effect in the distribution of delinquency scores, the scores were converted into a four-level ordinal variable. Associations were modelled using a proportional odds logistic regression model (Venables \& Ripley, 2002). The proportional odds model produces a single odds ratio for each explanatory variable that isassumed to apply equally to each transition between consecutive levels of delinquency as measured on the ordinal variable. A model including all explanatory variables was fitted using each of the 30 imputed data sets and the model results were then pooled. The assumptions underlying the proportional odds model were evaluated. All analyses were conducted in R version 3.2.0 (R Core Team, 2015).

\section{Results}

\subsection{Sample Characteristics}

Youth assessments were completed for $\mathrm{N}=950$ children, with approximately equal numbers of boys and girls. Nearly half of the cohort (47\%) identified themselves as Samoan, with 23\% Tongan, 14\% Cook Islanders, and the rest were grouped as "Other" which refers to youth from smaller Pacific ethnic groups (15\%). About one in eight children were potentially exposed to IPV (Table 1).

\subsection{Delinquency Outcomes}

The prevalence of delinquent behaviors ranged widely (Table 2). At the least serious end, two items (staying out later than parents said they should and lying to parents) were each reported by about one in three children. At the most delinquent end, one child admitted to having tried drugs, another to having helped to sell drugs and a further two children admitted to having gotten drunk.

\subsection{Rasch Analysis}

Eight children $(0.8 \%)$ were excluded from the analysis due to having four or more missing values among the 24 items. Occasional missing values on the remaining 942 children were assumed to be a "No" response, to retain them for the analysis. The Rasch analysis process eliminated two questions (the two most prevalent) as not 
Table 1. Sample characteristics $\left(\mathrm{N}=950^{*}\right)$.

\begin{tabular}{|c|c|c|c|}
\hline Variable & Level & $\mathbf{N}$ & $(\%)$ \\
\hline \multirow[t]{2}{*}{ Sex } & Female & 481 & $(51)$ \\
\hline & Male & 469 & $(49)$ \\
\hline \multirow[t]{4}{*}{ Youth ethnicity } & Samoan & 450 & $(47)$ \\
\hline & Tongan & 218 & $(23)$ \\
\hline & Cook Islands Maori & 136 & $(14)$ \\
\hline & Other & 146 & $(15)$ \\
\hline \multirow[t]{3}{*}{ Belonging to multiple ethnic groups } & Yes, but no difficulties & 194 & $(20)$ \\
\hline & Yes, and it causes difficulties & 178 & (19) \\
\hline & No, single ethnic group & 578 & $(61)$ \\
\hline \multirow[t]{4}{*}{ Baseline income (NZD p.a.) } & Under $\$ 20 \mathrm{k}$ & 318 & $(34)$ \\
\hline & From $\$ 20 \mathrm{k}$ but under $\$ 40 \mathrm{k}$ & 486 & $(51)$ \\
\hline & $\$ 40 \mathrm{k}$ and over & 118 & $(12)$ \\
\hline & Unknown & 28 & (3) \\
\hline Mother single & Yes & 200 & $(21)$ \\
\hline \multirow[t]{2}{*}{ Mother's education } & Up to secondary & 505 & $(53)$ \\
\hline & Beyond secondary & 440 & $(47)$ \\
\hline Mother smokes & Yes (any) & 314 & $(33)$ \\
\hline Maternal alcohol consumption & Yes (any) & 351 & $(37)$ \\
\hline \multirow[t]{4}{*}{ Maternal acculturation } & Assimilation & 398 & $(42)$ \\
\hline & Separation & 277 & $(29)$ \\
\hline & Integration & 96 & $(10)$ \\
\hline & Marginalization & 175 & $(19)$ \\
\hline \multirow[t]{2}{*}{ Maternal psychological distress } & Non symptomatic & 793 & $(84)$ \\
\hline & Symptomatic & 155 & $(16)$ \\
\hline Externalising child behavior & Yes & 256 & $(27)$ \\
\hline Intimate partner violence & Yes & 127 & (13) \\
\hline
\end{tabular}

${ }^{*}$ Totals below 950 indicate missing values.

appearing to measure the same construct as the others (Table 2). An acceptable fit to the Rasch model was therefore derived using the remaining 22 items. This model placed the children on the latent delinquency dimension by assigning each a delinquency score. Because 472 children (50\%) responded "No" to all 22 questions, the distribution of scores displayed a considerable floor effect and a strong right skewness. Scores were therefore categorized into a four-level ordinal variable for the purpose of regression analysis of associations (Figure 1).

\subsection{Statistical Model}

The proportional odds assumption was tested with a likelihood ratio test that compared the regression model with a multinomial model having separate transition odds for each explanatory variable. No evidence of a violation of the assumption was found $\left(\mathrm{X}^{2}=39.7 ; \mathrm{df}=70 ; p=0.99\right)$ thus the simpler proportional odds model was acceptable. 
Table 2. Prevalence for individual delinquency questions from LONGSCAN Risk Behaviors Questionnaire (14 items), Revised Olweus Bully/Victim Questionnaire (8 items) and Gang Membership Inventory (2 items), showing overall sample prevalence within each of the four derived delinquency level groupings.

\begin{tabular}{|c|c|c|c|c|c|c|c|}
\hline \multirow[b]{2}{*}{ Question } & \multirow[b]{2}{*}{$\mathbf{N}$} & \multirow[b]{2}{*}{ Yes } & \multirow[b]{2}{*}{$(\%)$} & \multicolumn{4}{|c|}{ Prevalence (\%) per level } \\
\hline & & & & 1 & 2 & 3 & 4 \\
\hline Ever tried cigarettes & 947 & 25 & 2.6 & 0.0 & 0.0 & 3.8 & 12.3 \\
\hline Ever tried alcohol & 947 & 41 & 4.3 & 0.0 & 3.4 & 9.0 & 14.1 \\
\hline Ever tried drugs & 947 & 1 & 0.1 & 0.0 & 0.0 & 0.0 & 0.6 \\
\hline Has anyone ever tried to sell you drugs at school & 940 & 9 & 1.0 & 0.0 & 0.6 & 1.5 & 3.7 \\
\hline Ever helped anyone sell drugs & 946 & 1 & 0.1 & 0.0 & 0.0 & 0.0 & 0.6 \\
\hline Ever stayed out later than your parents said you should* & 944 & 325 & 34.4 & 25.3 & 36.8 & 42.9 & 50.9 \\
\hline Ever hurt someone badly enough to need bandages or a doctor & 946 & 86 & 9.1 & 0.0 & 9.2 & 21.1 & 25.8 \\
\hline Ever lied to your parents about something important ${ }^{*}$ & 941 & 326 & 34.6 & 19.1 & 41.3 & 46.6 & 62.6 \\
\hline Ever taken something from a shop without paying for it & 946 & 65 & 6.9 & 0.0 & 4.0 & 9.0 & 28.2 \\
\hline Ever damaged school property on purpose & 946 & 38 & 4.0 & 0.0 & 1.1 & 6.8 & 16.6 \\
\hline Ever gotten drunk & 939 & 2 & 0.2 & 0.0 & 0.0 & 0.8 & 0.6 \\
\hline Ever had to bring your parents to school because of something you did wrong & 946 & 131 & 13.8 & 0.0 & 13.8 & 25.6 & 44.2 \\
\hline Ever stayed out at least one night without permission & 946 & 68 & 7.2 & 0.0 & 9.8 & 9.0 & 23.3 \\
\hline Ever skipped a day at school without permission or wagged school & 946 & 51 & 5.4 & 0.0 & 4.0 & 10.5 & 18.4 \\
\hline Called another student(s) mean names, made fun of or teased in a hurtful way & 943 & 236 & 25.0 & 0.0 & 27.6 & 43.6 & 79.8 \\
\hline Excluded or completely ignored another student & 941 & 93 & 9.9 & 0.0 & 7.5 & 18.0 & 34.8 \\
\hline Hit, kicked, pushed and shoved around or locked another student indoors & 943 & 125 & 13.3 & 0.0 & 9.2 & 17.3 & 52.1 \\
\hline Spread false rumours and tried to make others dislike another student & 943 & 48 & 5.1 & 0.0 & 2.3 & 5.3 & 22.7 \\
\hline Took money or other things from or damaged belongings of another student & 943 & 18 & 1.9 & 0.0 & 0.6 & 0.0 & 9.8 \\
\hline Threatened or forced another student to do things & 942 & 24 & 2.5 & 0.0 & 0.6 & 4.5 & 10.5 \\
\hline Bullied another student about race or skin colour & 942 & 42 & 4.5 & 0.0 & 0.0 & 3.8 & 22.8 \\
\hline Bullied another student with a sexual meaning & 943 & 31 & 3.3 & 0.0 & 2.9 & 3.0 & 13.5 \\
\hline Gang involvement in terms of wearing gang colours or using gang signs & 944 & 69 & 7.3 & 0.0 & 2.9 & 6.0 & 34.6 \\
\hline Gang representation such as spray painting gang signs or getting into fights & 945 & 18 & 1.9 & 0.0 & 0.6 & 1.5 & 9.3 \\
\hline
\end{tabular}

*These two items were excluded from the Rasch model.

\subsection{Associations}

Regression analyses revealed that boys exhibited greater delinquency than girls ( $\mathrm{AOR}=1.33, p<0.05)$. Some ethnic variation was evident, with the "Other" group having close to half the odds of delinquency compared to Samoans (AOR $=0.56, p<0.01)$, although neither Tongans nor Cook Islands Māori were different from Samoans. Among children who identified with multiple ethnic groups, those who reported that it led to difficulties had higher odds of delinquency than those who didn't (AOR $=1.68, p<0.05$ ), whereas those with a single ethnic identification showed no difference. In addition, some variation with maternal acculturation revealed that compared to the assimilator group (low Pacific, high NZ), the odds of delinquency in the integrator group (high Pacific, high NZ) was significantly lower (AOR $=0.56, p<0.05)$.

The biggest risk factor was peer pressure with the strongest effect (largest AOR) on delinquency (AOR = 


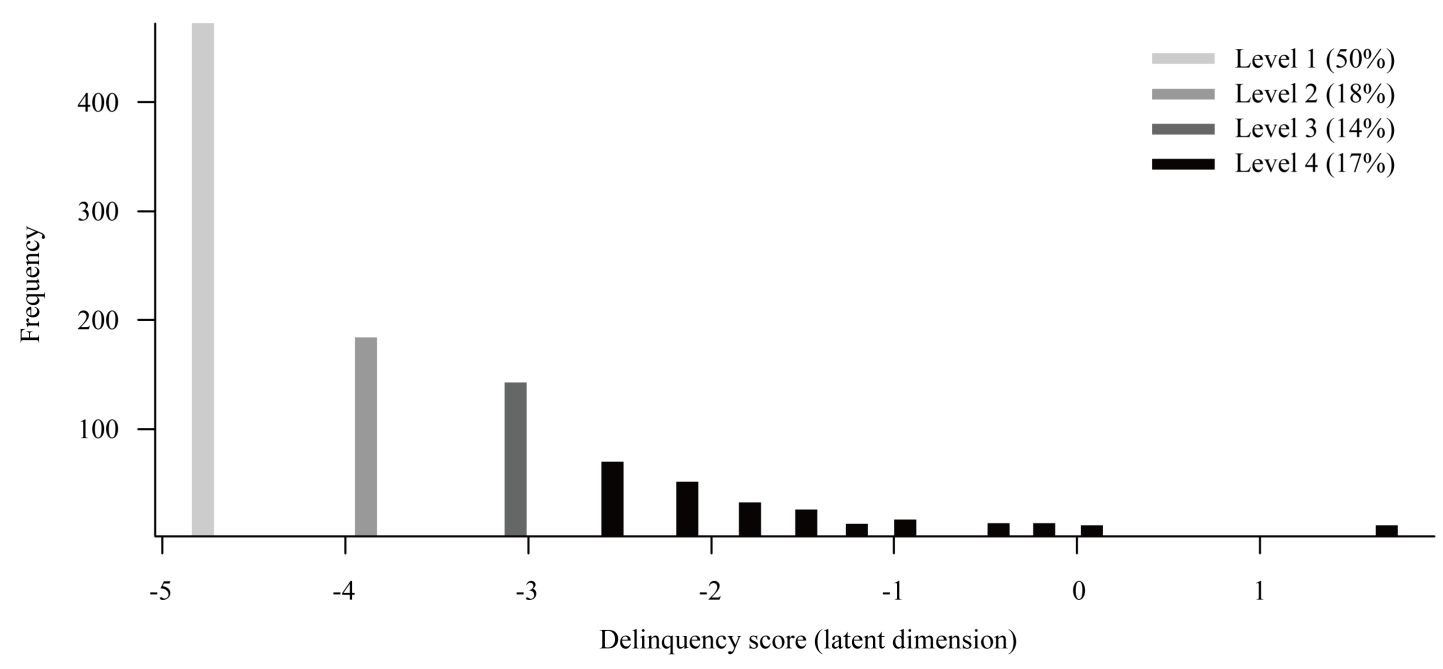

Figure 1. Distribution of delinquency scores derived from a Rasch model, divided into four levels.

3.20, $p<0.001$ ). Greater perceived support from a special person increased the odds of delinquency (AOR $=$ 1.29 per scale step, $p<0.05$ ), whereas greater perceived support from friends decreased it (AOR $=0.82, p<$ 0.05 ). Higher self-perception appeared strongly protective against delinquency (AOR $=0.50$ per scale step, $p<$ 0.001 ), and higher teacher evaluation scores were also inversely associated (AOR $=0.79$ per scale step, $p<$ 0.05 ). No other significant associations were observed ( $p>0.05$ for the remaining variables) as presented in Table 3.

\section{Discussion}

Consistent with other studies (Thompson et al., 2011), we found that Pacific boys were more likely than Pacific girls to engage in delinquent behaviors. It is suggested that there is a normative developmental trajectory of increasing delinquent behavior, starting in adolescence, with boys showing more delinquent behavior across the whole period of adolescence (Bongers, Coot, van der Ende, \& Verhulst, 2003; Moffitt \& Caspi, 2001). However, a small group of boys (10\%) and girls (1\%) may follow a life-course-persistent trajectory (Moffitt, 1993). Continuity between externalising behavior in childhood and delinquent behaviors in early adolescence has been demonstrated in some studies (Farrington, 1997; Thompson et al., 2011), however we found no association between earlier behavior and delinquency in this cohort.

In line with other studies we found the strongest risk factor for delinquency was peer pressure (Gifford-Smith, Dodge, Dishion, \& McCord, 2005; Lipsey \& Derzon, 1988). Deviant peer affiliation is described as a stronger predictor of delinquent behavior than other variables such as family, school, and community (Elliott \& Menard, 1996). Conversely, spending time with prosocial peers may curb involvement in delinquent behaviour (Elliott, 1994). This is highlighted by the significant association we found between perceived support from friends and lower levels of involvement in delinquent behaviours.

There are wide disparities in educational success currently faced by Pacific youth in NZ (Education Review Office, 2013). We found a significant association between high teacher-rated scholastic performance scores and lower levels of involvement in delinquency behaviors. Other studies have shown a strong correlation between low school achievement and delinquency (Moffitt, 1993). Low self-esteem (Rosenberg, Schooler, \& Schoenbach, 1989), low academic achievement, and low aspirations (Herrenkohl, Hawkins, Chung, Hill, \& BattinPearson, 2001) place youth at high risk for delinquency. Consistent with these findings, we found that youth with positive self-perceptions reported significantly lower levels of delinquent behaviour.

Youth from the largest Pacific groups, Tongan, Samoan, and Cook Islands Māori, reported similar delinquent behaviours but the "other" group (youth from smaller Pacific ethnic groups), had half the odds of delinquency compared with the reference group (Samoan). New Zealand's Pacific people are a dynamic and diverse group represented by at least thirteen distinctive languages and traditions. Although these cultural differences may have some influence on youth behaviour it is likely that the smaller number of participants in the "other" group in the PIF cohort may have impacted on this finding. 
Table 3. Adjusted odds ratios for associations with delinquent behaviour.

\begin{tabular}{|c|c|c|c|}
\hline Variable (reference group) & Category & AOR & $95 \%$ CI \\
\hline Sex (Female) & Male & 1.33 & $(1.02,1.75)^{*}$ \\
\hline \multirow[t]{3}{*}{ Youth ethnicity (Samoan) } & Tongan & 1.11 & $(0.81,1.54)$ \\
\hline & Cook Islands Māori & 0.80 & $(0.52,1.21)$ \\
\hline & Other & 0.56 & $(0.36,0.87)^{* *}$ \\
\hline \multirow[t]{2}{*}{ Multiple ethnicities (Yes, but no problem) } & Yes, and it's a problem & 1.68 & $(1.11,2.55)^{*}$ \\
\hline & No, just single ethnicity & 1.18 & $(0.82,1.70)$ \\
\hline \multirow[t]{3}{*}{ Baseline income (Under \$20k p.a.) } & $\$ 20-40 \mathrm{k}$ & 0.98 & $(0.74,1.31)$ \\
\hline & $\$ 40 \mathrm{k}^{+}$ & 1.07 & $(0.69,1.66)$ \\
\hline & Unknown & 1.82 & $(0.89,3.73)$ \\
\hline \multirow[t]{2}{*}{ Household size (2 - 4 members) } & 5 - 7 members & 0.94 & $(0.64,1.38)$ \\
\hline & 8 or more & 0.86 & $(0.56,1.32)$ \\
\hline Mother single (No) & Yes & 1.10 & $(0.78,1.55)$ \\
\hline Mother’s education (up to secondary) & Beyond secondary & 1.20 & $(0.91,1.58)$ \\
\hline Mother smokes (No) & Yes & 0.97 & $(0.72,1.30)$ \\
\hline Mother drinks alcohol (No) & Yes & 1.14 & $(0.84,1.56)$ \\
\hline \multirow[t]{3}{*}{ Mother's cultural orientation group (Assimilation) } & Separation & 1.30 & $(0.87,1.94)$ \\
\hline & Integration & 0.56 & $(0.34,0.92)^{*}$ \\
\hline & Marginalization & 1.02 & $(0.69,1.49)$ \\
\hline Mother’s GHQ (non-symptomatic) & Symptomatic & 1.33 & $(0.94,1.86)$ \\
\hline Parental involvement ${ }^{\dagger}$ & & 1.24 & $(0.91,1.70)$ \\
\hline Positive parenting $^{\dagger}$ & & 0.88 & $(0.63,1.23)$ \\
\hline Poor monitoring/supervision ${ }^{\dagger}$ & & 1.24 & $(0.86,1.78)$ \\
\hline 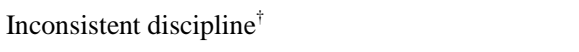 & & 1.06 & $(0.83,1.34)$ \\
\hline Corporal punishment $^{\dagger}$ & & 1.14 & $(0.93,1.39)$ \\
\hline Previous externalising (No) & Yes & 1.20 & $(0.89,1.60)$ \\
\hline Goes to church (No) & Yes & 0.86 & $(0.60,1.22)$ \\
\hline Language at home (Pacific) & English & 0.94 & $(0.69,1.27)$ \\
\hline Self-perception score ${ }^{\dagger}$ & & 0.50 & $(0.36,0.71)^{* * *}$ \\
\hline Intimate partner violence (No) & Yes & 1.10 & $(0.75,1.62)$ \\
\hline Peer pressure (No) & Yes & 3.20 & $(2.25,4.56)^{* * *}$ \\
\hline Special person score ${ }^{\dagger}$ & & 1.29 & $(1.02,1.61)^{*}$ \\
\hline Family support score ${ }^{\dagger}$ & & 0.84 & $(0.66,1.07)$ \\
\hline Friend support score ${ }^{\dagger}$ & & 0.82 & $(0.68,1.00)^{*}$ \\
\hline Teacher evaluation score ${ }^{\dagger}$ & & 0.79 & $(0.63,0.98)^{*}$ \\
\hline WASI score (standardised) ${ }^{\dagger}$ & & 0.97 & $(0.78,1.19)$ \\
\hline
\end{tabular}

AOR $=$ Adjusted Odds Ratio, $\mathrm{CI}=$ confidence interval, ${ }^{\dagger}$ per step on scale; ${ }^{*} p<0.05,{ }^{* *} p<0.01,{ }^{* * *} p<0.001$. 
Maternal acculturation was also significantly associated with delinquent behaviour, with youth whose mothers who were categorized as integrators (high Pacific/high NZ) having lower odds for youth delinquency than youth of mothers who were categorized as assimilators (low Pacific/high NZ). This indicates that mothers who move easily between cultures and are highly connected to both Pacific culture and NZ culture provide a cultural family context that protects against engagement in delinquent behaviour. Some Pacific youth in the cohort identified with multiple ethnic groups and those who reported that it led to difficulties had higher odds of delinquency than those who did not reveal difficulties.The involvement of Pacific youth in delinquent behavior is complicated by the socio-cultural constructs and values within the diverse Pacific communities in NZ. Pacific writers suggest that many Pacific youth struggle to forge an identity as they often do not affiliate with traditional social and cultural values of their parents or those of their country of birth (Mulitalo, 2001; Tiatia, 1996), potentially contributing to an increased risk of delinquent behaviour. Moreover, Pacific youth in NZ may be appropriating global cultures to create their own self-identifications with a number of Pacific youth adopting an ethos around urban rap and street gangs (Tupuola, 2000, 2004).

\section{Strengths and Limitations}

The longitudinal PIF Study provides information from a large and culturally diverse cohort of Pacific youth within NZ (Paterson et al., 2008). The questionnaires are administered in interview format by trained researchers which contribute to reliability and validity. However, some participants may under-report their behaviours due to the social unacceptability of revealing delinquent behaviours. These limitations are acknowledged; however in large scale studies such as the PIF Study, self-report is usually the most feasible option for measurement.

There is no single path to delinquency, however these findings suggest that feeling good about oneself during the school years through strong peer relationships and educational success is likely to set in motion the pathway to a positive future. Building up self-esteem, providing opportunities for young people to achieve (Rutter, 1987), and designing anti-delinquency measures in the school context are likely to contribute to a decrease in delinquent behavior. Building positive peer relationships by harnessing the power of prosocial peers has had demonstrable success in reducing antisocial and delinquent behavior (Harrell, Cavanagh, \& Sridharan, 1999).

Accessible and appropriate services for Pacific youth are needed to help young people realize their full potential (Ministry of Social Development, 2009), and interventions need to be created for Pacific youth that consider the overarching context of Pacific cultural traditions. Further in-depth research is necessary to explore the issues that youth from diasporic cultural backgrounds face as they progress through adolescence and find their place in the world.

\section{Acknowledgements}

The PIF Study is funded by the Foundation for Research, Science \& Technology, and the Health Research Council of New Zealand. The authors gratefully acknowledge the study participants and the PIF Advisory Board.

\section{References}

Achenbach, T. M., \& Rescorla, L. A. (2000). Manual for the ASEBA Preschool Forms \& Profiles. Burlington, VT: University of Vermont, Department of Psychiatry.

Begg, D. J., \& Gulliver, P. (2008). A Longitudinal Examination of the Relationship between Adolescent Problem Behaviors and Traffic Crash Involvement during Young Adulthood. Traffic Injury Prevention, 9, 508-514. http://dx.doi.org/10.1080/15389580802335117

Bongers, I. L., Koot, H. M., van der Ende, J., \& Verhulst, F. C. (2003). The Normative Development of Child and Adolescent Problem Behavior. Journal of Abnormal Psychology, 112, 179-192. http://dx.doi.org/10.1037/0021-843X.112.2.179

Borrows, J., Williams, M., Schluter, P., Paterson, J., \& Langitoto Helu, S. (2011). Pacific Islands Families Study: The Association of Infant Health Risk Indicators and Acculturation of Pacific Island Mothers Living in New Zealand. Journal of Cross-Cultural Psychology, 42, 699-724. http://dx.doi.org/10.1177/0022022110362750

Boston, J., \& Chapple, S. (2014). Child Poverty in New Zealand. Wellington: Bridget Williams Books. http://dx.doi.org/10.7810/9781927247860

Broidy, L. M., Nagin, D. S., Tremblay, R. E., Brame, R., Dodge, K., Fergusson, D. M., Horwood, L. J., Loeber, R., Laird, R., Lynam, D. R., \& Moffitt, T. E. (2003). Developmental Trajectories of Childhood Disruptive Behavior Disorders and 
Adolescent Delinquency: A Cross-National Replication. Developmental Psychology, 39, 222-245. http://dx.doi.org/10.1037/0012-1649.39.2.222

Canty-Mitchell, J., \& Zimet, G. D. (2000). Psychometric Properties of the Multidimensional Scale of Perceived Social Support in Urban Adolescents. American Journal of Community Psychology, 28, 391-400. http://dx.doi.org/10.1023/A:1005109522457

Dadds, M. R., Maujean, A., \& Fraser, J. A. (2003). Parenting and Conduct Problems in Children: Australian Data and Psychometric Properties of the Alabama Parenting Questionnaire. Australian Psychologist, 38, 236-241. http://dx.doi.org/10.1080/00050060310001707267

Education Review Office. (2013). Secondary Schools: Pathways for Future Education, Training and Employment. The ChildThe Heart of the Matter. Wellington: Education Evaluation Report. http://www.ero.govt.nz/

Elliott, D. S. (1994). Serious Violent Offenders: Onset, Developmental Course, and Termination-The American Society of Criminology 1993 Presidential Address. Criminology, 32, 1-21. http://dx.doi.org/10.1111/j.1745-9125.1994.tb01144.x

Elliott, D. S., \& Menard, S. (1996). Delinquent Friends and Delinquent Behavior: Temporal and Developmental Patterns. In J. D. Hawkins (Ed.), Delinquency and Crime: Current Theories (pp. 28-67). Cambridge Criminology Series, New York: Cambridge University Press.

Farrington, D. P. (1997). Early Prediction of Violent and Non-Violent Youthful Offending. European Journal on Criminal Policy and Research, 5, 51-66. http://dx.doi.org/10.1007/BF02677607

Frick, P. J., Christian, R. C., \& Wooten, J. M. (1999). Age Trends in the Association between Parenting Practices and Conduct Problems. Behavior Modification, 23, 106-128. http://dx.doi.org/10.1177/0145445599231005

Gifford-Smith, M., Dodge, K. A., Dishion, T. J., \& McCord, J. (2005). Peer Influence in Children and Adolescents: Crossing the Bridge from Developmental to Intervention Science. Journal of Abnormal Child Psychology, 33, 255-265. http://dx.doi.org/10.1007/s10802-005-3563-7

Goldberg, D., \& Williams, P. A. (1988). A User's Guide to the GHQ. Windsor: NFER-Nelson.

Harkness, C., Murray, S., Parkin, M., \& Dalgety, J. (2005). Pasifika Achievement Engagement and Choice. Wellington, Ministry of Education.

Harrell, A. V., Cavanagh, S. E., \& Sridharan, A. (1999). Evaluation of Children at Risk Program: Results One Year after the Program. Washington DC: US National Institute of Justice.

Herrenkohl, T. I., Hawkins, J. D., Chung, I. J, Hill, K. G., \& Battin-Pearson, S. (2001). School and Community Risk Factors and Interventions. In R. Loeber, \& D. P. Farrington (Eds.), Child Delinquents: Development, Intervention and Service Needs (pp. 211-246). Thousand Oaks, CA: Sage. http://dx.doi.org/10.4135/9781452229089.n10

Ioane, J., Lambie, I., \& Percival, T. (2013). A Review of the Literature on Pacific Island Youth Offending in New Zealand. Aggressive \& Violent Behavior, 18, 426-433. http://dx.doi.org/10.1016/j.avb.2013.05.002

Jose, P. E, Ryan, N., \& Pryor, J. E. (2012). Does Social Connectedness Lead to a Greater Sense of Well-Being in Adolescence? Journal of Research on Adolescence, 22, 235-251. http://dx.doi.org/10.1111/j.1532-7795.2012.00783.X

Jose, P. E., \& Schurer, K. (2010). Cultural Differences in Coping among New Zealand Adolescents. Journal of Cross-Cultural Psychology, 41, 3-18. http://dx.doi.org/10.1177/0022022109348783

Lipsey, M. W., \& Derzon, J. H. (1988). Predictors of Violent or Serious Delinquency in Adolescence and Early Adulthood: A Synthesis of Longitudinal Research. In R. Loeber, \& D. P. Farrington (Eds.), Serious and Violent Juvenile Offenders: Risk Factors and Successful Interventions (pp. 86-105). Thousand Oaks, CA: Sage.

Mair, P., Hatzinger, R., \& Maier, M.J. (2015). eRm: Extended Rasch Modeling.

Makowska, Z., Merecz, D., Moscicka, A., \& Kolasa, W. (2002). The Validity of General Health Questionnaires, GHQ-12 and GHQ-28, in Mental Health Studies of Working People. International Journal of Occupational Medicine and Environmental Health, 15, 353-362.

Marsh, H. (1994). Using the National Longitudinal Study of 1988 to Evaluate Theoretical Models of Self-Concept. The Self-Description Questionnaire, Journal of Educational Psychology, 86, 439-456. http://dx.doi.org/10.1037/0022-0663.86.3.439

Ministry of Business, Innovation \& Employment (2013). Youth Labour Market Factsheet-March 2013. Wellington, Ministry of Business, Innovation \& Employment.

Ministry of Health (2008). Pacific Youth Health: A Paper for the Pacific Health and Disability Action Plan Review. Wellington: Ministry of Health.

Ministry of Social Development (2009). Conduct Problems: Best Practice Report.

https://www.msd.govt.nz/documents/about-msd-and-our-work/publications-resources/research/conduct-problems-best-pra ctice/conduct-problems.pdf

Moffitt, T. E. (1993). Adolescence-Limited and Life-Course Persistent Antisocial Behavior: A Developmental Taxonomy. 
Psychological Review, 100, 674-701. http://dx.doi.org/10.1037/0033-295X.100.4.674

Moffitt, T. E., \& Caspi, A. (2001). Childhood Predictors Differentiate Life-Course Persistent and Adolescent Limited Antisocial Pathways among Males and Females. Development \& Psychopathology, 13, 355-375. http://dx.doi.org/10.1017/S0954579401002097

Mulitalo, T. (2001). My Own Shade of Brown. Christchurch: Shoal Bay Press.

Nakhid, C. (2009). The Meaning of Family and Home for Young Pacific People Involved in Gangs in the Suburbs of South Auckland. Social Policy Journal of New Zealand, 35, 112-128.

Office of the Prime Minister's Science Advisory Committee (2011). Improving the Transition, Reducing Social and Psychological Morbidity during Adolescence. A Report from the Prime Minister's Chief Science Advisor, Wellington.

Olweus, D. (1996). The Revised Olweus Bully/Victim Questionnaire. Research Center for Health Promotion (HEMIL Center), Bergen: University of Bergen.

Paterson, J., Percival, T., Schluter, P., Sundborn, G., Abbott, M., Carter, S., Cowley-Malcolm, E., Borrows, J., \& Gao, W. (2008). Cohort Profile: Pacific Islands Families (PIF) Study. International Journal of Epidemiology, 37, $273-279$. http://dx.doi.org/10.1093/ije/dym171

Perry, B. (2014). Household Incomes in New Zealand: Trends in Indicators of Inequality and Hardship 1982 to 2013. Wellington: Ministry of Education.

Pillen, M., \& Hoewing-Roberson, R. (1992). Determining Youth Gangs Membership: Development of a Self-Report Instrument. ERIC Document Reproduction Service No. ED 352412, Bloomington, IL: Chestnut Health Systems.

R Core Team (2015). R: A Language and Environment for Statistical Computing. Vienna: R Foundation for Statistical Computing. http://www.R-project.org/

Rasch, G. (1960). Probabilistic Models for Some Intelligence and Attainment Tests. Copenhagen: Danish Institute for Educational Research.

Rescorla, L. A., Achenbach, T. M., Ivanova, M. Y., Harder, V. S., Otten, L., Bilenberg, N., \& Verhulst, F. C. (2011). International Comparisons of Behavioral and Emotional Problems in Preschool Children: Parents' Reports from 24 Societies. Journal of Clinical Child and Adolescent Psychology, 40, 456-467. http://dx.doi.org/10.1080/15374416.2011.563472

Rosenberg, M., Schooler, C., \& Schoenbach, C. (1989). Self-Esteem and Adolescent Problems: Modeling Reciprocal Effects. American Sociological Review, 54, 1004-1018. http://dx.doi.org/10.2307/2095720

Rutter, M. (1987). Psychosocial Resilience and Protective Mechanisms. American Journal of Orthopsychiatry, 57, $316-331$. http://dx.doi.org/10.1111/j.1939-0025.1987.tb03541.x

Sang, D., \& Ward, C. (2006). Acculturation in Australia and New Zealand. In D. L. Sam, \& J. W. Berry (Eds.), Cambridge Handbook of Acculturation Psychology (pp. 253-273). Cambridge: Cambridge University Press. http://dx.doi.org/10.1017/CBO9780511489891.021

Saunders, J. B., Aasland, O. G., \& Babor, T. F. (1993). Development of the Alcohol Use Disorders Identification Test (AUDIT): WHO Collaborative Project on Early Detection of Persons with Harmful Alcohol Consumption. Addiction, 88, 791-804. http://dx.doi.org/10.1111/j.1360-0443.1993.tb02093.x

Statistics New Zealand (2013). 2013 Census. Wellington: Government of New Zealand.

Statistics New Zealand and Ministry of Pacific Island Affairs (2011). Health and Pacific Peoples in New Zealand. Wellington: Statistics New Zealand and Ministry of Pacific Island Affairs.

Straus, M. A. (1979). Measuring Intrafamily Conflict and Violence: The Conflict Tactics (CT) Scales. Journal of Marriage and Family, 41, 75-88. http://dx.doi.org/10.2307/351733

Straus, M. A. (1990). Measuring Intrafamily Conflict and Violence: The Conflict Tactics (CT) Scales. In M. A. Straus, \& R. J. Gelles (Eds.), Physical Violence in American Families: Risk Factors and Adaptations to Violence in 8,145 Families (pp. 49-71). New Brunswick, NJ: Transaction Books.

Tennant, A., \& Conaghan, P. G. (2007). The Rasch Measurement Model in Rheumatology: What Is It and Why Use It? When Should It Be Applied and What Should One Look for in a Rasch Paper? Arthritis \& Rheumatism, 57, 1358-1362. http://dx.doi.org/10.1002/art.23108

Thompson, R., Tabone, J. K., Litrownik, A. J., Briggs, E. C., Hussey, J. M., English, D. J., \& Dubowitz, H. (2011). Early Adolescent Risk Behavior Outcomes of Childhood Externalising Behavioral Trajectories. Journal of Early Adolescence, 31, 234-257. http://dx.doi.org/10.1177/0272431609361203

Tiatia, J. (1996). Caught between Two Cultures: A New Zealand Pacific Island perspective. Auckland: Christian Research Association.

Tsai, J. L., Ying, Y. W., \& Lee, P. A. (2000). The Meaning of “Being Chinese” and "Being American”: Variation among Chinese American Young Adults. Journal of Cross-Cultural Psychology, 31, 302-332. 
http://dx.doi.org/10.1177/0022022100031003002

Tupuola, A. M. (2000). To Be Ethnic Is to Be Cool—The Pasifika Flavour in New Zealand: A Cultural Renaissance or a Passing Trend? America 2000 Free Zone Symposium, New York: New York University.

Tupuola, A. M. (2004). Pasifika Edgewalkers: Complicating the Achieved Identity Status in Youth Research. Journal of Intercultural Studies, 25, 87-100. http://dx.doi.org/10.1080/07256860410001687045

Van Buuren, S., \& Groothuis-Oudshoorn, K. (2011). Mice: Multivariate Imputation by Chained Equations. Journal of Statistical Software, 45, 1-67. http://dx.doi.org/10.18637/jss.v045.i03

Venables, W. N., \& Ripley, B. D. (2002) Modern Applied Statistics with S (4th Ed.). New York: Springer. http://dx.doi.org/10.1007/978-0-387-21706-2

Wechsler, D. (2003). Wechsler Intelligence Scales for Children (4th Ed.). Technical and Interpretive Manual, New South Wales: The Psychological Corporation.

Williams, R. J., \& Nowatzki, N. (2005). Validity of Adolescent Self-Report of Substance Use. Journal of Substance Abuse and Misuse, 40, 299-311. http://dx.doi.org/10.1081/JA-200049327

Zimet, G. D., Dahlem, N. W., Zimet, S. G., \& Farley, G. K. (1988). The Multidimensional Scale of Perceived Social Support. Journal of Personality Assessment, 52, 30-41. http://dx.doi.org/10.1207/s15327752jpa5201_2

\section{Submit or recommend next manuscript to SCIRP and we will provide best service for you:}

Accepting pre-submission inquiries through Email, Facebook, Linkedin, Twitter, etc A wide selection of journals (inclusive of 9 subjects, more than 200 journals)

Providing a 24-hour high-quality service

User-friendly online submission system

Fair and swift peer-review system

Efficient typesetting and proofreading procedure

Display of the result of downloads and visits, as well as the number of cited articles

Maximum dissemination of your research work

Submit your manuscript at: http://papersubmission.scirp.org/ 